\title{
Histochemical detection of the lectin-binding carbohydrates in the zona pellucida during oocyte growth in the wild boar (Sus scrofa scrofa)
}

\author{
Francesco PARILlO ${ }^{\mathrm{a}^{*}}$, Silvana DIVERIO ${ }^{\mathrm{a}}$, \\ Luca TODINI $^{\mathrm{b}}$, Oliviero FAGIOLI ${ }^{\mathrm{b}}$ \\ ${ }^{\text {a }}$ Department of Biopathological Veterinary Science, Faculty of Veterinary Medicine, \\ Perugia University, via San Costanzo 4, 06126 Perugia, Italy \\ ${ }^{b}$ Department of Veterinary Science, Faculty of Veterinary Medicine, Camerino University, \\ via Circonvallazione 93/95, 62024 Matelica (MC), Italy
}

(Received 18 December 2000; accepted 18 June 2001)

\begin{abstract}
The changes that occur in the carbohydrate composition of zona pellucida glycoproteins during oocyte maturation in the wild-boar were studied using periodic-acid Schiff (PAS), High Iron Diamine (HID) and Low Iron Diamine (LID). Lectin staining was performed with a panel of 11 HRPlectin conjugates combined with neuraminidase digestion and chemical treatments. There were few internal glucidic residues, such as $\mathrm{N}$-acetylglucosamine, in the wild boar zona pellucida but there were many subterminal $\beta$ - $\mathrm{N}$-acetylgalactosamine, $\alpha$ - and $\beta$-galactose determinants masked by sialic acid. In addition, $\beta$ - $\mathrm{N}$-acetylgalactosamine, $\beta$-galactose-(1-3)- $\mathrm{N}$-acetylgalactosamine and $\beta$-galactose(1-4)-N- acetylglucosamine were detected in the sulphated form in the terminal and/or subterminal position. Some differences in the lectin reactive sites occurred in the zona pellucida, depending on the stage of oocyte maturation.
\end{abstract}

zona pellucida / glycoprotein / lectin-histochemistry / wild-boar

Résumé - Détection histochimique des carbohydrates liant les lectines dans la zone pellucide pendant la croissance de l'ovocyte chez le sanglier (Sus scrofa scrofa). Les changements apparaissant dans la composition en carbohydrates des glycoprotéines de la zone pellucide pendant la maturation des oocytes chez le sanglier ont été étudiés en utilisant l'acide périodique Schiff, la diamine riche en fer et la diamine pauvre en fer. La coloration des lectines a été réalisée en utilisant 11 conjugués lectine-péroxydase combinés à une digestion par la neuraminidase et des traitements chimiques. Il y avait peu de résidus glucidiques internes tels que la $\mathrm{N}$-glucosamine, présents dans la zone pellucide du sanglier mais il y avait de nombreux déterminants $\beta-\mathrm{N}$ acétylgalactosamines subterminaux et des déterminants $\alpha$ - et $\beta$-galactose masqués par de l'acide sialique. De plus, de la

\footnotetext{
* Correspondence and reprints
}

Tel.: (39) 75 5857631; fax: (39) 75 5857631; e-mail: silvana@unipg.it 
$\beta$-N acétylgalactosamine, $\beta$-galactose-(1-3)-N-acétylgalactosamine et de la $\beta$-galactose-(1-4)-N acétylglucosamine ont été détectées sous forme de sulfate en position terminale et/ou subterminale. Des différences dans les sites réactifs de lectines se sont produites dans la zone pellucide en fonction du stade de maturation de l'ovocyte.

zone pellucide / glycoprotéine / lectine / sanglier

\section{INTRODUCTION}

The zona pellucida (ZP), an extracellular envelope located around the mammalian oocytes, plays an important role in gamete interaction during fertilisation and early stages of zygote development. It is involved in species-specific sperm-egg binding, induction of acrosome interaction, post-fertilisation block to polyspermy and embryo protection during its transit along the reproductive tract [7, 26, 27]. Previous biochemical studies have demonstrated that the glycan portion of the glycoproteins ZPB of the pig [29] and of ZP3 [6, 24, 28] of the mouse may be the complementary sperm receptors mediating the primary binding between the spermatozoon and the ZP. These findings encouraged the use of plant lectins for the histochemical characterisation of the ZP glycoproteins in rats [3], humans [4] and various domestic mammals [12-17, 25]. In those studies, lectin-staining was combined with treatments such as neuraminidase, desulphation and saponification to explore the carbohydrate composition and linkage types of the oligosaccharide side chains which constitute the mammalian ZP glycoproteins.

Mori et al. [11] have described biochemical studies of acidic N-glycans of porcine ZP and Parillo et al. [14] have reported ZP histochemistry in domestic pigs. The present study was carried out to investigate the distribution patterns of the different oligosaccharidic side chains of ZP glycoproteins during oocyte growth of wild boar which are closely related to the domestic pig but presents different reproductive behaviour.

\section{MATERIALS AND METHODS}

\subsection{Tissue collection}

Ovaries from ten sexually mature wild boars (Sus scrofa L.) were collected from a licensed wild ungulate abbattoir. Specimens were fixed in Carnoy's fluid. Serial sections of paraffin-embedded tissues were stained with conventional and lectin histochemical methods as described in detail elsewhere [16]. Each stain was performed in duplicate. The staining of different components of the $\mathrm{ZP}$, ooplasm, granulosa cells and follicular fluid and intercellular matrix were evaluated subjectively on a semiquantitative scale: negative $(-)$, weak $(+)$, moderate $(++)$ and strong $(+++)$. Wild boar follicles were classified according to Pedersen and Peters [18].

\subsection{Conventional histochemical staining methods}

Samples were treated with periodic-acid Schiff (PAS) to detect glycoconjugates with vicinal hydroxyls, High Iron Diamine (HID) to discriminate sulphate groups, Low Iron Diamine (LID) to detect sulphate and carboxyl radicals.

\subsection{Lectin histochemistry}

Lectin histochemistry was performed using a modification of the procedure described by Schulte and Spicer [9, 21, 22]; full details are given elsewhere [16]. The horseradish peroxidase (HRP)-lectin conjugates and their hapten sugars are shown in Table I. Diaminobenzidine was used as a chromogen. 
Table I. Lectins used and their carbohydrate specificities.

\begin{tabular}{|c|c|c|}
\hline Source of lectin & $\begin{array}{l}\text { Acronym } \\
\text { of lectins }\end{array}$ & $\begin{array}{l}\text { Specificity of lectins } \\
\text { and inhibitory sugars }\end{array}$ \\
\hline Arachis hypogaea & PNA & $\beta$-D-Gal- $(1 \rightarrow 3)$-D-GalNAc \\
\hline Griffonia simplicifolia & GSA-II & $\alpha$ and $\beta$ GlcNAc \\
\hline Griffonia simplicifolia IB4 & GSA IB4 & $\alpha$-D-Galactose \\
\hline Ulex europaeus & UEA-I & $\alpha$-L-Fucose \\
\hline Lotus tetragonolobus & LTA & $\alpha$-L-Fucose \\
\hline Dolichos biflorus & DBA & $\alpha$-D-GalNAc \\
\hline Glycine max & SBA & $\alpha$-D-GalNAc $>\beta-D$-GalNAc \\
\hline Triticum vulgare & WGA & GlcNAc $>$ sialic acid \\
\hline Canavalia ensiformis & Con-A & $\alpha$-D-Man > $\alpha$-D-Glc \\
\hline Lens culinaris & LCA & $\alpha$-D-Man > $\alpha$-D-Glc \\
\hline Ricinus communis & RCA-I & $\beta$-D-Gal- $(1 \rightarrow 4)$-D-GlcNAc \\
\hline
\end{tabular}

a $\beta$-D-Gal $=\beta$-D-galactose $; \alpha-D-G a l=\alpha$-D-galactose $; D-G a l N A c=D-N$-acetylgalactosamine $; \beta$-D-GalNAc $=$ $\beta$-D-N-acetylgalactosamine; $\alpha-\mathrm{D}-\mathrm{GalNAc}=\alpha-\mathrm{D}-\mathrm{N}$-acetylgalactosamine; GlcNAc $=\mathrm{N}$-acetylglucosamine; $\alpha$-D-Man $=\alpha$-D-mannose; $\alpha$-D-Glc $=\alpha$-D-glucose.

Some lectin (SBA, PNA-, GSA IB4-, RCA-I-, DBA-, and GSA-II-) staining procedures were preceded by neuraminidase digestion, saponification or desulphation:

- neuraminidase (type V from Clostridium perfringens) (sialidase) digestion was carried out for $36 \mathrm{~h}$ at $37^{\circ} \mathrm{C}$ in a solution of $0.1 \mathrm{M}$ acetate buffer, $\mathrm{pH} 5.5$, and $10 \mathrm{mM} \mathrm{CaCl}_{2}$ containing the enzyme at a concentration of $0.86 \mathrm{U} / \mathrm{mL}$;

- saponification (deacetylation) to determine the presence of terminal sialic acid residues with $O$-acetyl groups resistant to sialidase treatment, was performed before neuraminidase treatment by immersing the sections in a $1 \%$ solution of potassium hydroxide $(\mathrm{KOH})$ in $70 \%$ ethanol for $15 \mathrm{~min}$ at room temperature [21];

- desulphation preceded lectin staining and sialidase digestion and consisted of sequential methylation-saponification (performed by immersion in $0.15 \mathrm{~N} \mathrm{HCl}$ in methanol $\left(5 \mathrm{~h}, 60^{\circ} \mathrm{C}\right)$ and then in a $1 \%$ solution of potassium hydroxide $(\mathrm{KOH})$ in $70 \%$ ethanol for $15 \mathrm{~min}$ at room temperature) [8].

\subsection{Controls}

Staining of duplicate sections acted as an internal control. Controls for enzymatic digestion were performed by the substitution of sialidase with buffer solution alone under the same incubation conditions. Controls for lectin histochemistry were performed by incubation in a solution containing conjugated lectins with the specific inhibitory sugar (0.2-0.4 M) or by omitting the lectin HRP-conjugates. The effectiveness of the desulphation technique was revealed confirmed by subsequent negative HID staining.

\section{RESULTS}

In the present study, the ZP, ooplasm, granulosa cells and follicular fluid/intercellular matrix showed positive reactions to complex carbohydrates; the reactivity was evaluated in preantral follicles (stage $3 \mathrm{~b}$ : one layer of follicle cells surrounds a growing oocyte; stage 4: two layers of follicle cells; stage 5a: three layers of follicle cells; 
stage 5b: many layers of follicle cells) and antral follicles (stages 6: a large oocyte with many layers of cells, scattered areas of follicular fluid; stage 7: a follicle with a single cavity, with a diameter $\leq 5 \mathrm{~mm}$, containing follicular fluid). The findings with conventional and lectin histochemistry are described briefly below.

\subsection{Conventional histochemical staining methods}

In both preantral and antral follicles, the $\mathrm{ZP}$ and follicular fluid/intercellular matrix strongly reacted with PAS (indicating the presence of glycoconjugates with vicinal hydroxyls) and HID (Fig. 1) and moderately with LID indicating the presence of sulphate groups but not of carboxylated radicals. There was no staining of the ooplasm and granulosa cells at any stage of follicular development.

\subsection{Lectin histochemistry}

The results of staining were identical in the duplicate sections and staining was absent in negative controls. There was no staining of any histological component, with or without pretreatments, with GSA-II, UEA-I, LTA, Con-A, LCA and DBA. Staining with SBA, PNA, GSA-IB4 and RCAI-lectin was also negative without pretreatment but occurred following sialidase digestion, with or without previous saponification, and/or desulphation.

WGA staining was not modified by sialidase digestion preceded also by saponification. The results (summarized in Tab. II) are described in more detail below.

Glycine maximus (SBA). SBA staining following neuraminidase digestion indicated the presence of $\beta$-GalNAc linked to sialic acid residues. There was uniform staining of the ZP (moderate in oocytes present in preantral follicles and strong in antral ones).

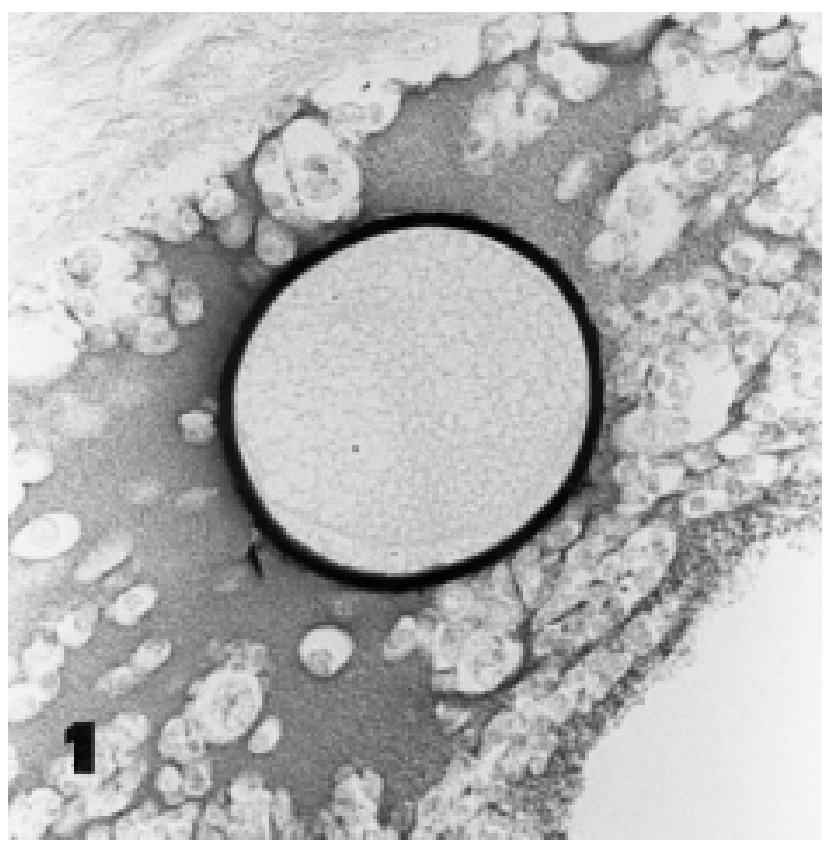

Figure 1. An antral follicle (stage 7). The zona pellucida and follicular fluid/intercellular matrix are strongly positive after HID staining. 400x. 
Table II. Semiquantitative evaluation of lectin-staining of different follicular components (zona pellucida, ooplasm, granulosa cells, follicular fluid and intercellular matrix) at different stages of follicular development (preantral [3b-5b] and antral [6-7]).

\begin{tabular}{|c|c|c|c|c|c|c|}
\hline $\begin{array}{l}\text { Pretreatment } \\
\text { lectin }\end{array}$ & $\begin{array}{l}\text { Sugar detected } \\
\text { and staining for } \\
\text { negative control }\end{array}$ & $\begin{array}{l}\text { Follicular } \\
\text { stage }\end{array}$ & $\begin{array}{l}\text { Zona } \\
\text { pellucida }^{b}\end{array}$ & Ooplasm & $\begin{array}{l}\text { Granulosa } \\
\text { cells }\end{array}$ & $\begin{array}{l}\text { Follicular } \\
\text { fluid and } \\
\text { intercellular } \\
\text { matrix }\end{array}$ \\
\hline \multirow{2}{*}{$\begin{array}{l}\text { Neuraminidase } \\
\text { SBA }\end{array}$} & \multirow{2}{*}{$\begin{array}{c}\beta \text {-D-GalNAc linked } \\
\text { to sialic acid }\end{array}$} & \multirow{2}{*}{$\begin{array}{c}(3 b, 4,5 a, 5 b) \\
(6-7)\end{array}$} & $++^{\mathrm{c}}$ & + & + & + \\
\hline & & & +++ & + & + & ++ \\
\hline \multirow{2}{*}{$\begin{array}{l}\text { Saponification } \\
\text { neuraminidase } \\
\text { SBA }\end{array}$} & \multirow{2}{*}{$\begin{array}{c}\beta \text {-D-GalNAc linked } \\
\text { to sialic acid } \mathrm{C}_{4} \\
\text { O-acetylated }\end{array}$} & $(3 b, 4,5 a, 5 b)$ & ++ & + & + & + \\
\hline & & $(6-7)$ & +++ & + & + & ++ \\
\hline \multirow{2}{*}{$\begin{array}{l}\text { Desulphation } \\
\text { SBA }\end{array}$} & \multirow{2}{*}{$\begin{array}{c}\mathrm{SO}_{4} \beta \text {-D- } \\
\text { GalNAc terminal }\end{array}$} & \multirow{2}{*}{$\begin{array}{c}(3 b, 4,5 a, 5 b) \\
(6-7)\end{array}$} & ++ & + & + & + \\
\hline & & & ++ & + & + & ++ \\
\hline \multirow{2}{*}{$\begin{array}{l}\text { Desulphation } \\
\text { neuraminidase } \\
\text { SBA }\end{array}$} & \multirow{2}{*}{$\begin{array}{c}\mathrm{SO}_{4} \beta \text {-D-GalNAc } \\
\text { subterminal }\end{array}$} & \multirow{2}{*}{$\begin{array}{c}(3 b, 4,5 a, 5 b) \\
(6-7)\end{array}$} & +++ & + & + & + \\
\hline & & & +++ & + & + & + \\
\hline \multirow{2}{*}{$\begin{array}{l}\text { Saponification } \\
\text { neuraminidase } \\
\text { PNA }\end{array}$} & \multirow{2}{*}{$\begin{array}{c}\beta \text {-D-Gal linked } \\
\text { to sialic acid } C_{4} \\
\text { O-acetylated }\end{array}$} & $(3 b-4)$ & + & - & - & ++ \\
\hline & & $(5 \mathrm{a}, 5 \mathrm{~b}, 6,7)$ & ++ & - & - & ++ \\
\hline \multirow{3}{*}{$\begin{array}{l}\text { Desulphation } \\
\text { PNA }\end{array}$} & \multirow{3}{*}{$\begin{array}{c}\mathrm{SO}_{4} \beta-\mathrm{D}-\mathrm{Gal} \\
\text { terminal }\end{array}$} & $(3 b-4)$ & + & - & - & ++ \\
\hline & & $(5 a-5 b)$ & ++ & - & - & ++ \\
\hline & & $(6-7)$ & $++* 1$ & + & + & ++ \\
\hline \multirow{3}{*}{$\begin{array}{l}\text { Desulphation } \\
\text { neuraminidase } \\
\text { PNA }\end{array}$} & \multirow{3}{*}{$\begin{array}{c}\mathrm{SO}_{4} \beta-\mathrm{D}-\mathrm{Gal}- \\
(1 \rightarrow 3)-\mathrm{D}-\text { GalNAc } \\
\text { subterminal }\end{array}$} & $(3 b-4)$ & ++ & - & - & ++ \\
\hline & & $(5 a-5 b)$ & +++ & - & - & ++ \\
\hline & & $(6-7)$ & +++ & + & + & ++ \\
\hline \multirow{2}{*}{$\begin{array}{l}\text { Saponification } \\
\text { neuraminidase } \\
\text { GSA-IB4 }\end{array}$} & \multirow{2}{*}{$\begin{array}{c}\alpha-D-G a l \text { linked } \\
\text { to sialic acid } C_{4} \\
\text { O-acetylated }\end{array}$} & \multirow{2}{*}{$\begin{array}{c}(3 b, 4,5 a-5 b) \\
(6-7)\end{array}$} & \multirow{2}{*}{$\begin{array}{l}++ \\
++\end{array}$} & \multirow{2}{*}{$\begin{array}{l}- \\
-\end{array}$} & \multirow{2}{*}{$\begin{array}{l}- \\
-\end{array}$} & \multirow{2}{*}{ - } \\
\hline & & & & & & \\
\hline $\begin{array}{l}\text { Desulphation } \\
\text { neuraminidase } \\
\text { RCA-I }\end{array}$ & $\begin{array}{c}\mathrm{SO}_{4} \beta-\mathrm{D}-\mathrm{Gal}- \\
(1 \rightarrow 4)-\mathrm{D}-\mathrm{GlcNAc} \\
\text { subterminal }\end{array}$ & $(3 b, 4,5 a, 5 b, 6,7)$ & + & - & - & - \\
\hline \multirow[t]{2}{*}{ WGA } & \multirow[t]{2}{*}{ GlcNAc } & \multirow{2}{*}{$\begin{array}{c}(3 b, 4,5 a, 5 b) \\
(6-7)\end{array}$} & ++ & + & + & - \\
\hline & & & $+++* 2$ & + & + & - \\
\hline
\end{tabular}

${ }^{\text {a }}$ Blocking sugar for negative control.

b Uniform staining unless otherwise indicated: $* 1$ external only; $* 2$ internal and external.

c (-) negative, $(+)$ weak, $(++)$ moderate, $(+++)$ strong reaction.

There was weak staining of ooplasm and granulosa cells at all follicular stages; staining of follicular fluid/intercellular matrix was weak in preantral follicles and moderate in antral ones. SBA staining following desulphation indicated the presence of terminal $\mathrm{SO}_{4}-\beta-$-GalNAc. There was uniform moderate staining of the $\mathrm{ZP}$ of all the oocytes examined and weak positivity of the ooplasm and granulosa cells; the 
reactivity of the follicular fluid/intercellular matrix was weak in preantral follicles and moderate in antral ones; this staining strongly increased in the ZP after desulphation/sialidase/SBA sequence indicating the presence of $\mathrm{SO}_{4}-\beta$-GalNAc linked to sialyl residues (Neu5Ac- $\mathrm{SO}_{4}-\beta-$ GalNAc). Saponification with $\mathrm{KOH}$ did not increase affinity for SBA.

Arachis hypogaea (PNA). PNA staining following saponification/sialidase sequence indicated the presence of Gal- $\beta$ 1,3GalNAc linked to sialic acid with $\mathrm{C} 4$ acetyl substituentes. In the $\mathrm{ZP}$, homogeneous staining was weak in the oocytes present in stages $3 b-4$ follicles and moderate in those of stages 5a-7; ooplasm and granulosa cells were unstained whereas there was moderate staining of follicular fluid/intercellular matrix. PNA staining after desulphation technique indicated the presence of terminal $\mathrm{SO}_{4}$-Gal- $\beta$-1,3GalNAc. There was uniform staining in the ZP of preantral oocytes, weak in oocytes of stages $3 b-4$ and moderate in oocytes of stages 5a-5b; on the contrary, PNA staining (moderate) was confined to the external layer of the ZP in antral oocytes; ooplasm and granulosa cells staining (weak) occurred only in antral follicles; there was moderate staining of follicular fluid/intercellular matrix at all stages. Staining increased after desulphation/sialidase pretreatment, indicating the presence of $\mathrm{SO}_{4^{-}}$ Gal- $\beta$-1,3GalNAc subterminal to sialic acid residues (Neu5Ac- $\mathrm{SO}_{4}$-Gal- $\beta$-1,3GalNAc) (Fig. 2).

\section{Griffonia simplicifolia IB4 (GSA IB4).} GSA IB4-binding occurred only after saponification/sialidase sequence indicating the presence of $\alpha$-Gal linked to sialic acid acetylated at $\mathrm{C} 4$. The staining was moderately and uniformly distributed in the ZP of both preantral and antral oocytes.

Ricinus communis I (RCA-I). Staining with RCA-I disclosed a weak and homogeneous labelling after desulphation/sialidase sequence only of the ZP of both preantral

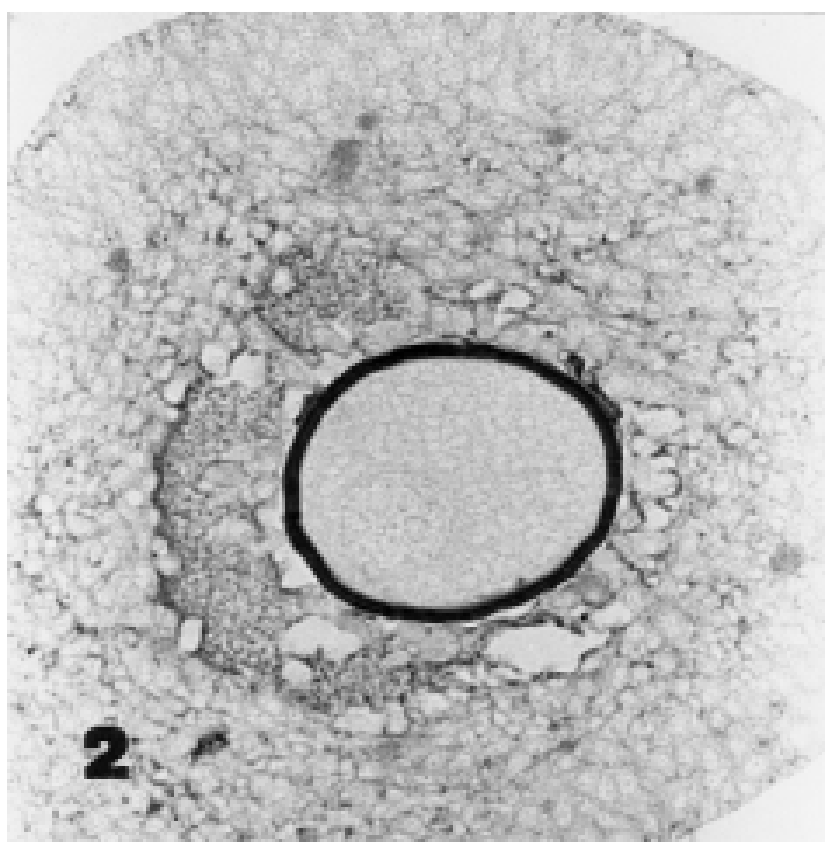

Figure 2. An antral follicle (stage 6). Desulphation/sialidase/PNA-HRP staining. PNA reactive sites are evenly and strongly distributed in the ZP; ooplasm and granulosa cells are weakly stained, follicular fluid/intercellular matrix moderately. 400x. 
and antral oocytes indicating the presence of $\mathrm{SO}_{4}$-Gal- $\beta-1,4 \mathrm{GlcNAc}$ subterminal to sialic acid moieties (Neu5Ac- $\mathrm{SO}_{4}$-Gal- $\beta$ 1,3GalNAc).

Triticum vulgaris (WGA). WGA staining, indicating the presence of GlcNAc residues, was moderate and uniform in the ZP of preantral oocytes and strong but localized in the external and internal surfaces of the ZP in antral oocytes (Fig. 3). Ooplasm and granulosa cells resulted weakly reactive in prentral and antral follicles; follicular fluid/intercellular matrix did not react with this lectin in both types of follicles. Sialidase digestion, with or without prior saponification, did not modify WGA reactivity.

\subsection{Controls}

Staining for lectins was completely inhibited when the lectin-HRP conjugates were preincubated with the appropriate hapten sugar or when they were omitted from the incubation medium. Desulphation procedure abolished HID reactivity in control sections.

\section{DISCUSSION}

Traditional staining methods demonstrated the presence of complex carbohydrates, rich in vic-glycol and sulphate groups (PAS and HID strongly positive), in wild boar ZP and follicular fluid/intercellular matrix of preantral and antral follicles, whereas carboxyl radicals (moderate LID positivity) were absent. This heterogeneity of glucidic composition of wild boar ZP was confirmed by SBA-, PNA-, GSA-IB4-, RCA-I- and WGA-lectins which showed differential binding affinity. Moreover, lectin histochemistry in conjunction with sialidase digestion and chemical treatments provided more detailed information on the chemical structure of the oligosaccharide chains of
Figure 3. An antral follicles (stage 7). WGA-HRP staining. WGA labelling sites are distributed strongly and unevenly in the inner and outer portions; ooplasm and granulosa cells react weakly whereas follicular fluid/intercellular matrix are unreactive. 400x.

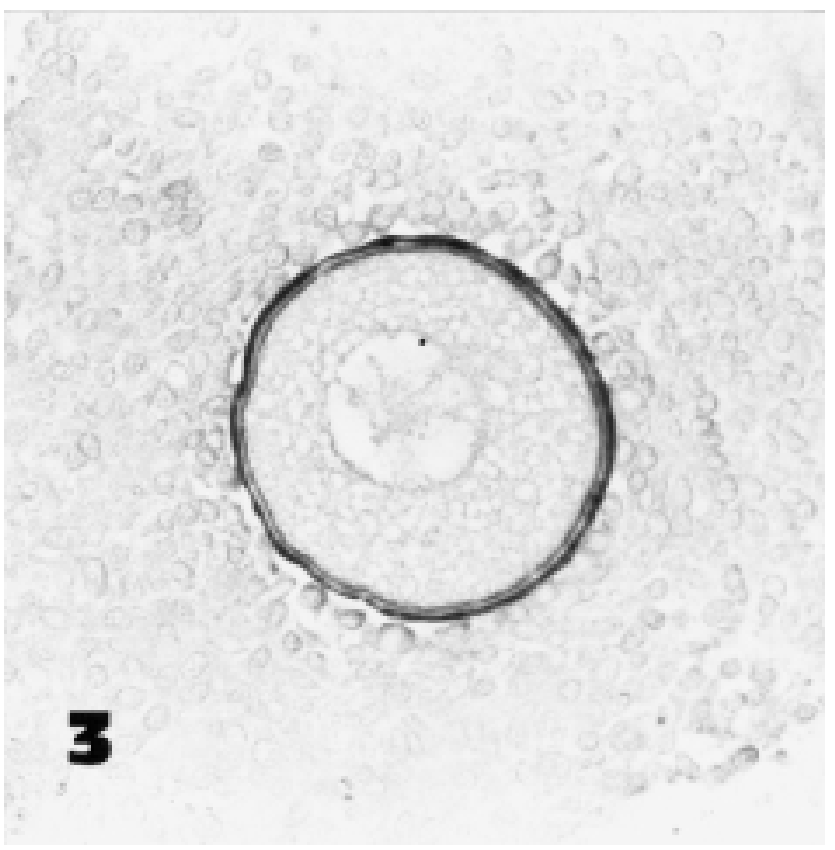


glycocoproteins in the wild boar ZP and on the nature of the linkage between the glucidic and polypeptide components.

Lectin-staining of ooplasm, granulosa cells and intercellular matrix/follicular fluid showed a very similar lectin affinity. In particular, the following carbohydrates were detected: $\mathrm{SO}_{4}-\beta \mathrm{GalNAc}$ and Neu5Ac$\beta$ GalNAc residues in all the above sites of both preantral and antral follicles; $\mathrm{SO}_{4} \mathrm{Gal}$ $\beta 1,3 \mathrm{GalNAc}$ moieties in ooplasm/granulosa cells in follicles of stages 6-7 and in follicular fluid/intercellular matrix of all follicles; Neu5Ac-Gal- $\beta 1,3$ GalNAc residues in intercellular matrix/follicular fluid of all the follicles examined and GlcNAc residues only in ooplasm and granulosa cells of preantral and antral follicles.

$\mathrm{SO}_{4}-\beta$ GalNAc, Neu5Ac- $\beta$ GalNAc and $\mathrm{SO}_{4}$ Gal- $\beta 1,3 \mathrm{GalNAc}$ residues occurred also in the follicular fluid of early developing follicles in rabbit and hare follicles (unpublished data).

There is more information concerning ZP lectin-binding in other species; the amount and distribution of the glycocomponents of wild boar ZP during oocyte growth were generally similar to those observed in other animals [16]. The main differences in carbohydrate composition were related to the spatial distribution of $\mathrm{SO}_{4} \mathrm{Gal}-\beta 1,3 \mathrm{GalNAc}$ and GlcNAc residues.

The presence in both preantral and antral oocytes of wild boar ZP of the two main families of glycoproteins (having $\mathrm{N}$ - or $\mathrm{O}$ glycosidic links) is similar to that in the $\mathrm{ZP}$ of domestic species [12-16, 25].

Like the ZP of livestock, the glycoproteins of the wild boar ZP were highly sialylated and sulphated. Sialic acid moieties were only demonstrated indirectly by sequential enzymatic and chemical treatments, suggesting the presence of GalNAc (sialidase/SBA), $\beta$-Gal ( $\mathrm{KOH} /$ sialidase/ PNA) and $\alpha-G a l(\mathrm{KOH} /$ sialidase/GSA-IB4), linked to terminal sialic acid residues. Desulphation before lectin histochemistry revealed that terminal GalNAc and $\beta$-Gal residues contained $\mathrm{SO}_{4}$ groups. Increased staining with some lectins after sequential desulphation/sialidase indicated that they acted as receptors for sialic acids.

In particular, the terminal dimer sialic acid- $(\alpha 2 \rightarrow 6)$-GalNAc and $\mathrm{SO}_{4}$ GalNAc residues were detected in the $\mathrm{ZP}$ of all oocytes whereas subterminal $\mathrm{SO}_{4}$ GalNAc was identified only in the ZP of preantral oocytes. The absence of DBA-binding sites indicated that galactosamine residues were present in the $\beta$-anomeric form, as has been previously reported in domestic species [12-16, 25].

Deacetylation with $\mathrm{KOH}$, prior to sialidase digestion, was necessary in order to demonstrate PNA staining of the ZP for the terminal trisaccharide sialic acid- $(\alpha 2 \rightarrow 3,6)$ $\beta$-Gal-(1-3)-GalNAc.

The trisaccharides sialic acid $(\alpha 2 \rightarrow 3,6)$ $\beta$-Gal-(1-4)-GlcNAc (sialidase/RCA-I) and the disaccharide $\mathrm{C} 4$ acetylated sialic acid $(\alpha 2 \rightarrow 3,6)-\alpha-G a l(\mathrm{KOH} /$ sialidase/GSA-IB4) were present in oocytes in preantral and antral follicles as well as glucosamine residues situated in the internal and terminal positions (WGA) [1, 2]. Staining with WGA and RCA-I but not with GSA-II, suggests that $\mathrm{N}$-acetylglucosamine occupied an internal rather than terminal position. The absence of any reduction of WGA labelling by sialidase degradation, even after saponification, indicates that sialic acid did not compete with $\mathrm{N}$-acetylglucosamine for WGA [10].

Non uniform staining in antral oocytes for $\mathrm{SO}_{4} \beta-\mathrm{D}-\mathrm{Gal}$ (1-3)-D-GalNAc (desulphation/PNA) and GlcNAc was similar to that previously reported in various domestic mammals using lectins at light microscopy $[14-16,25]$ and confirmed in the rat [3] and hamster [19] at ultrastructural level; the ZP appears to be composed of a number of concentric zones, each characterised by different types and distribution patterns of the oligosaccharide chains.

Sialyl-rich glycoproteins $(\beta-\mathrm{N}-$ GalNAc [sialidase/SBA], $\alpha$ - and $\beta-\mathrm{Gal}$ 
[sialidase/GSA-IB4 and sialidase/PNA]) were well represented in the wild boar ZP and have also been demonstrated in various species [3, 5, 11-16, 23, 25] including humans [4]. Schauer [20] suggested that sialic acids confer a rigidity to the $\mathrm{ZP}$, facilitating the penetration of the spermatozoon during fertilisation. Moreover, the presence of other highly negatively charged constituents, including the $\mathrm{SO}_{4}$ groups of carbohydrates, help to favour the adherence of the interacting gametes. Large amounts of sulphoglycans were demonstrated in wild boar ZP and in many of the above mentioned animal species.

There were many similarities between the lectin binding patterns (in particular with SBA and PNA lectins after sialidase digestion and saponification and with WGA) of antral oocytes in wild boar ZP and those of the pig, a closely related species [14]. Some differences, however, were revealed: pretreatment followed by SBA and PNA showed that $\mathrm{SO}_{4}$ GalNAc and $\mathrm{SO}_{4} \mathrm{Gal}$ $\beta 1,3 \mathrm{GalNAc}$ occupied a terminal position in the wild boars whereas the same carbohydrates were demonstrated in the penultimate position (linked to sialic acid) in pigs. In addition, Neu5Ac- $\alpha-\mathrm{Gal}(\mathrm{KOH} / \mathrm{siali}$ dase/GSA-IB4) and $\mathrm{SO}_{4} \mathrm{Gal}-\beta 1,4 \mathrm{GlcNAc}$ (desulphation/RCA-I) moieties were identified in the wild boar whereas in the pig there were Neu5Ac-SO ${ }_{4} \alpha$-Gal (desulphation/sialidase/GSA-IB4), Neu5Ac-Gal$\beta 1,4 \mathrm{GlcNAc}$ (sialidase/RCA-I) and Neu5Ac-GlcNAc (sialidase/GSA-II) residues. There were more pronounced differences in the lectin affinity of the ZP between the wild-boar and distantly related species (eg cats and dogs). Differences in carbohydrate sequence, as well as in the relative amounts of each glycocomponent, on the surface of the ZP among mammals may play a significant role in determining species specific sperm-egg recognition, restricting interspecies fertilisation.

In conclusion, variations in the amount and distribution of the glycocomponents of the wild boar ZP during oocyte growth were generally similar to those described in other animals [16]. The main differences in the carbohydrates composition of the wild boar ZP during oocyte maturation were essentially related to the spatial distribution of $\mathrm{SO}_{4}$ Gal- $\beta 1,3 \mathrm{GalNAc}$ and GlcNAc residues.

\section{ACKNOWLEDGEMENTS}

The authors wish to thank Dr. Luca Pecchia for his technical assistance. Research was supported by Italian MURST (60\%).

\section{REFERENCES}

[1] Accili D., Menghi G., Bondi A.M., Scocco P., Glycoconjugate composition of mammalian parotid glands elucidated in situ by lectins and glycosidases, Acta Histochem. 92 (1992) 196206.

[2] Allen A.K., Neuberger A., Sharon N., The purification, composition and specificity of wheat germ agglutinin, Biochem. J. 131 (1973) 155-159.

[3] Avilés M., Martinez-Menarguez J.A., Castells M.T., Madrid J.F., Ballesta J., Cytochemical characterization of oligosaccharide side chains of the glycoproteins of rat zona pellucida: an ultrastructural study, Anat. Rec. 239 (1994) 137-149.

[4] Bar-Shira Maymon B., Maymon R., Ben-Nun I., Ghetler Y., Shalgi R., Skutelsky E., Distribution of carbohydrates in the zona pellucida of human oocytes, J. Reprod. Fertil. 102 (1994) 81-86.

[5] Delgado M.N., Zoller L.C., A quantitative and qualitative cytochemical analysis of glycosaminoglycan content in the zona pellucida of hamster ovarian follicles, Histochemistry 87 (1987) 279-287.

[6] Fayrer-Hosken R., Featured article: understanding the mechanisms of gamete interaction for optimizing embryo production and evaluating fertility, Embryo Transfer Newsletter 12 (1994) 14-17.

[7] Macek M.B., Shur B.D., Protein-carbohydrate complementary in mammalian gamete recognition, Gamete Res. 20 (1988) 93-109.

[8] Martinez-Menarguez J.A., Ballesta J., Avilès M., Madrid J.F., Castells M.T., Influence of sulphated groups in the binding of peanut agglutinin. Histochemical demonstration with light and electron-microscopy, Histochem. J. 24 (1992) 207216.

[9] Menghi G., Reactivity of peroxidase-labelled lectins in rabbit submandibular and sublingual glands, Acta Histochem. 75 (1984) 27-35. 
[10] Monsigny M., Roche A.C., Sene C., Maget-Dana R., Delmotte F., Sugars-lectin interactions: how does wheat germ agglutinin bind sialoglycoconjugates? Eur. J. Biochem. 104 (1980) 147-152.

[11] Mori E., Hedrick J.L., Wardrip N.J., Mori T., Takasaki S., Occurrence of reducing terminal Nacetilglucosamine 3-sulfate and fucosylated outer chains in acidic N-glycans of porcine zona pellucida glycoproteins. Glycoconjugate J. 15 (1998) 447-456.

[12] Parillo F., Verini Supplizi A., Stradaioli G., Tortora G., Chiacchiarini P., Monaci M., Lectin binding sites on oocyte zona pellucidae in superovulated cattle, Proceedings 10th Sci. Meeting of the Association Européenne de Transfert Embryonnaire, Lyon, 1994, p. 232.

[13] Parillo F., Verini Supplizi A., Stradaioli G., Tortora G., Monaci M., Identificazione istochimica mediante lectine dei glicoconiugati della zona pellucida di ovocellule di bovine sottoposte a trattamento superovulatorio, Acta Med. Vet. (Napoli) 40 (1994) 215-221.

[14] Parillo F., Stradaioli G., Dall'Aglio C., Verini Supplizi A., Characterization of the complex carbohydrates in the zona pellucida of mammalian oocytes using lectin histochemistry, Vet. Res. Comm. 20 (1996) 225-236.

[15] Parillo F., Stradaioli G., Verini Supplizi A., Glycoconjugates in small antral ovarian follicles of the River buffalo (Bubalus bubalis L.), Acta Histochem. 100 (1998) 1-15.

[16] Parillo F., Verini Supplizi A., Glycohistochemical investigation of canine and feline zonae pellucidae of mammalian of preantral and antral oocytes, Acta Histochem. 101 (1999) 1-20.

[17] Parillo F., Fagioli O., Dall'Aglio C., Verini Supplizi A., Lectin histochemical detection of sulfoglycans in the zona pellucida of mammalian antral oocytes, Acta Histochem. 102 (2000) 1-10.

[18] Pedersen T., Peters H., Proposal for a classification of oocytes and follicles in the mouse ovary, J. Reprod. Fertil., 17 (1968) 555-557.
[19] Roux E., Kan F.W.K., Changes of glycoconjugate contents of the zona pellucida during oocyte growth and development in the golden hamster: a quantitative study, Anat. Rec. 230 (1991) 347360 .

[20] Schauer R., Chemistry, metabolism and biological functions of sialic acids, Adv. Carbohydr. Chem. Biochem. 40 (1982) 131-234.

[21] Schulte B.A., Spicer S.S., Light microscopic detection of sugar residues in glycoconjugates of salivary glands and the pancreas with lectinhorseradish peroxidase conjugates I Mouse, Histochem. J. 22 (1983) 1217-1238.

[22] Spicer S.S., Schulte B.A., Detection and differentiation of glycoconjugates in various cell types by lectin histochemistry, Basic Appl. Histochem. 32 (1988) 307-320.

[23] Tadano Y., Yamada K., The histochemistry of complex carbohydrates in the ovarian follicles of adult mice, Histochemistry 57 (1978) 723-731.

[24] Tulsiani D.R.P., Yoshida-Komiya H., Araki Y., Mammalian fertilization: a carbohydrate-mediated event, Biol. Reprod. 57 (1997) 487-494.

[25] Verini Supplizi A., Monaci M., Stradaioli G., Greve T., Parillo F., Identification of glycoconjugates in the zona pellucida of in vitro matured and tubal unfertilized bovine oocytes by lectin histochemistry, Anim. Reprod. Sci. 43 (1996) 99111.

[26] Wassarman P.M., Profile of a mammalian sperm receptor, Development 108 (1990) 1-17.

[27] Wassarman P.M., Gamete interactions during mammalian fertilization, Theriogenology 41 (1994) 31-44.

[28] Wassarman P.M., Mortillo S., Structure of the mouse egg extracellular coat, the zona pellucida, Int. Rev .Cytol. 130 (1991) 85-110.

[29] Yonezawa N., Mitsui S., Kudo K., Nakano M., Identification of an N-glycosylated region of pig zona pellucida glycoprotein ZPB that is involved in sperm binding. Eur. J. Biochem. 248 (1997) 86-92. 